\title{
A contrassexualidade como superação das dicotomias de gênero e sexo
}

\author{
Manifesto Contrassexual. Políticas \\ subversivas de identidade sexual. \\ PRECIADO, Beatriz. \\ São Paulo: $\mathrm{n}$-1 edições, 2014, 223 p.
}

O espanhol Paul B. Preciado, nascido Beatriz Preciado, é um dos filósofos feministas que mais tem se destacado no cenário de debates da teoria queer e dos estudos de gênero desde o início da década de 2000 , juntamente com outras autoras como Judith Butler, Sue Ellen Case e Eve Sedgwick. Conhecido notoriamente por ter feito a autoadministração de testosterona para analisar os efeitos que este hormônio provocaria em seu corpo, publicou o livro Testo Yonqui (2008), no qual analisa o modo como as estruturas políticas e de poder - sobretudo as capitalistas representadas pela indústria pornográfica e farmacológica - influenciam as experiências subjetivas das pessoas e a maneira como vive-se o corpo. Mas foi certamente o livro Manifiesto Contrasexual, publicado pela primeira vez na França em 2000, que o tornou uma das principais referências no campo de debate dos estudos queer e de gênero, propondo a contrassexualidade como um conjunto de análises críticas e subversivas às categorias fixas de identidade d@sujeit@, principalmente aquelas ligadas ao sexo, gênero e sexualidade.Para@s estudios@s brasileir@s que se interessam por estas investigações, o livro só podia ser encontrado em língua espanhola ou inglesa até que, em 2014, a editora n-1 traduziu e publicou Manifesto Contrassexual, livro dividido em quatro capítulos e anexo que podem ser lidos separadamente, pois em cada um deles é desenvolvida uma reflexão diferente sobre a temática proposta.

Manifesto contrassexual tem uma característica singular: é um texto performativo, situando-se nas fronteiras e bordas entre teoria, prática e ensaio. Os quatro capítulos resultaram das experiências que Preciado teve na França no final da década de 1990 com o grupo Le Zoo, cuja reivindicação mais significativa consistia na inclusão de disciplinas sobre Estudos de Gênero e Estudos Gays e Lésbicos nas universidades francesas, de modo a compensar a orientação e a matriz heterossexuais de outras disciplinas ensinadas. Sua colaboração foi importante para este grupo, para o qual ele preparou um seminário entre 1999 e 2000, e que por fim resultou neste livro. Vale lembrar que Preciado se insere na tradição do feminismo americano e da teoria queer dos anos 1990 , especialmente nos debates do Center for LGBTQ Studies (CLAGS) de Nova York, dado que sua política contrassexual rompe com toda a série de binômios tradicionais que tem servido como fundamento da filosofia moderna e da própria reflexão feminista que vinha sendo debatida na década de 1990.

E qual é a proposta do manifesto contrassexual? Preciado defende no primeiro capítulo intitulado "Contrassexualidade", a análise crítica da diferença de gênero e de sexo que comumente costumam ser julgados como produto de explicações essencialistas e biológicas da heteronormatividade. Aliado a isso, ele não rejeita a hipótese das construções sociais ou psicológicas de gênero, mas as ressitua, ou melhor, desloca-as, como mecanismos de um sistema tecnológico mais amplo. Tanto o sexo quanto $\circ$ gênero e a sexualidade seriam resultados de dispositivos inscritos em um sistema tecnológico e sociopolíitico complexo: "homem", 
"mulher", "homossexual", "heterossexual", "transexual" não passam de máquinas, produtos, instrumentos, redes, conexões, fluxos de energia e de informação, usos e desvios que incidem sobre o corpo. Entretanto, o corpo não pode ser compreendido como matéria passiva ou um mero receptáculo de todos os discursos e práticas de gênero que atuam nele uma vez que se deve considerar sua própria manifestação. Aqu percebemos a presença de uma gramática profundamente assentada na filosofia francesa pós-estruturalista, em especial em Derrida e Deleuze, autores com quem ele mantém interlocução até o final do último capítulo. Desse modo, a contrassexualidade tem como tarefa o estudo dos instrumentos e dos dispositivos sexuais, das relações de gênero e sexo que se estabelecem entre corpo e máquina/técnica com a finalidade de desnaturalizar as noções tradicionais de sexo e de gênero.

As explicações introdutórias de Preciado acerca da contrassexualidade se alinham às ideias centrais da heterossexualidade do regime político de Monique Wittig, dos dispositivos sexuais pensados por Michel Foucault, às análises da identidade performativa de Judith Butler e à política do ciborgue, de Donna Haraway. Mas sua principal interlocutora é, de fato, Judith Butler, com a qual estabelece muitos pontos em comum, principalmente na solução dada para superarmos os modelos explicativos de gênero pautados na oposição "construção social versus natureza" (Beatriz PRECIADO, 2014, p. 23). Tal como esta filósofa, Preciado critica o feminismo construtivista ao dizer que o gênero não é somente um efeito das práticas culturais linguísticodiscursivas, dando forma e significado ao corpo conforme a cultura ou o momento histórico. Ao mesmo tempo, de modo algum ele se alia aos modelos explicativos pautados na natureza e na biologia, como se um cromossomo fosse determinar o gênero e a sexualidade d@ sujeit@. A solução que ele sugere para superarmos tais explicações é muito semelhante ao que Judith Butler pontuou pela primeira vez, em 1993, em Bodies that Matter: a ideia de perfomatividade'. Preciado, por sua vez, busca outro termo nessa busca, ou seja, o gênero seria, antes de tudo, prostético e que não se dá senão na materialidade dos corpos. Baseando-se nas noções de "transversalidade", de Deleuze, e de "desconstrução", de Derrida, que foi seu orientador no final da década de 1990, Preciado entende o gênero como algo que é constante e puramente construído e, ao mesmo tempo, inteiramente orgânico (PRECIADO, 2014, p. 29).
Entretanto, Preciado evita entender o gênero somente como atos da perfomatividade, pois para ela essa alusão é insuficiente para refletir os processos através dos quais os corpos (re)assumem a sexualidade e o gênero. É nesse sentido que o filósofo, em 2000 , pretendeu dar um passo a mais em relação ao texto canônico da teoria queer, Gender Trouble (1990), pois, para ele, Judith Butler subestimou os processos corporais e especialmente as transformações sexuais presentes nos corpos transexuais e transgêneros. Foi apenas em Undoing Gender (2004) e em outros livros posteriores que Judith Butler irá problematizar os corpos que haviam ficado invisíveis anteriormente, poucos anos depois de Preciado ter publicado Manifiesto Contrasexual. Portanto, a contrassexualidade de Preciado tem como tarefa identificar os espaços errôneos e as falhas da estrutura social-discursiva, considerando a importância dos lugares ocupados pelos corpos dos "intersexuais, hermafroditas, loucas, caminhoneiras, bichas, sapas, bibas, fanchas, butchs, histéricas, saídas ou frígidas, hermafrodykes, reforçando o poder dos desvios e derivações em relação ao sistema heterocentrado" (PRECIADO, 2014, p. 27).

No breve capítulo 2, "Práticas de inversão contrassexual", Preciado propõe o termo "dildotectônica" para esclarecer de que maneira o dildo - noção dedicada ao "sexo de plástico" - interfere e compõe tecnicamente no sistema sexo/gênero. A dildotectônica seria, portanto, um ramo importante da contrassexualidade por supor - corpo como superfície móvel, terreno de deslocamento e de localização do dildo. Um dos primeiros exemplos que ele utiliza para descrever de que maneira a "dildotectônica" funciona na prática refere-se à performance e body-art do artista americano Ron Athey. Suas apresentações ao vivo, no final da década de 1990, aglutinam práticas artísticas de diferentes estéticas, apontando questionamentos e reapropriações dos meios de comunicação de massa para (re)produzir práticas de gênero e sexualidade dissidentes. Para além da performatividade de gênero, Preciado chama atenção para as transformações corporais, físicas e sexuais de Athey que não se realizam apenas no palco, e sim no espaço público. Ademais, esse capítulo também traz a crítica à cultura heterocentrada, na qual o corpo funciona decisiva e majoritariamente a serviço da reprodução sexual e da produção de prazer genital. Trata-se de resistir à normalização da masculinidade e da feminilidade em nossos corpos, e de inventar outras formas de prazer e 
de convivência. Dito de outro modo, o universo das sensibilidades e dos prazeres precisaria ser deslocado do órgão sexual masculino para outras áreas do corpo, invertendo, ou melhor, subvertendo a lógica heternormativa que investe o pênis como o principal produtor de prazer para si e para@s outr@s.

"Teorias" é o título dado para o terceiro capítulo que se diferencia dos demais por se mais filosófico. A discussão principal é mostrar como o sexo, pelo menos a partir do século XVIII, é o resultado de uma tecnologia biopolítica. Isto é, Preciado reflete sobre o processo de todo um complexo sistema de estruturas reguladoras que controlam a relação entre os corpos com a sexualidade e os usos atribuídos a eles. E importante nesse contexto a releitura de Foucault acerca da noção de tecnologia, a qual tinha sido repudiada tanto pelo feminismo clássico quanto pelas políticas anticoloniais, uma vez que era entendida como índice de dominação masculina. Além da presença de Foucault, o livro Manifesto Ciborgue (1989), de Donna Haraway, também marcará um ponto de inflexão para a repolitização de categorias como o feminino, o animal, a natureza - que haviam sido pensados precisamente na própria fronteira da tecnologia biopolítica.

Mas o que mais chama atenção em "Teorias" são as respostas que Preciado elabora a uma série de perguntas formuladas no começo do livro. Como aproximar-se do sexo enquanto objeto de análise? Que fatos históricos e sociais intervêm na produção de gênero? Pode-se falar e escrever sobre a sexualidade e o gênero heterossexual sendo gay ou lésbica? Ou, ao contrário, pode-se falar sobre a sexualidade e o gênero de gays e lésbicas sendo heterossexual? Novamente ele traz em cena o dildo, investindo-o como o primeiro indicador da plasticidade sexual do corpo e da possível modificação prostética que advém dele. Em outras palavras, o dildo indica que os órgãos masculinos e femininos que interpretamos como essencialmente naturais já tenham sofrido um processo de transformação plástica desde o século XVIII. E, sobre este assunto, ele provoca mais ainda ao dizer: "se o dildo suscita a reprovação na comunidade lésbica $e$ nas representações em geral é porque esse incômodo brinquedo nos faz compreender que os verdadeiros pênis não passam de dildos" (PRECIADO, 2014, p. 79). A lógica do dildo, portanto, prova que os próprios termos dos pares binários heterossexual/homossexual, masculino/ feminino, ativo/passivo não passam de elementos de um sistema arbitrário de significação.
O último capítulo conclui o ciclo de debates subversivos na medida em que Preciado pretende articular a noção de "homossexualidade molecular" de Deleuze e Guattari com o "devir mulher". Conforme sua argumentação, é possível pensar ou escrever transversalmente sobre certos fenômenos sem passar pela experiência real. Em Deleuze, a transversalidade adquire nova força de teoria e prática política, convertendo-se em condição de possibilidade de certas experiências de "devir". A homossexualidade, assim como o alcoolismo e a drogadição por exemplo, não estão no âmbito da identidade ou da essência e sim do devir. Entretanto, Preciado assume a dificuldade de compreender o sentido da afirmação "sou um homossexual molecular" de Deleuze, uma vez que ele era heterossexual, pois não há ainda respostas para as seguintes perguntas: "quais são os mecanismos de transversalidade e as passagens de conversões que tornam Deleuze um homossexual"? "Quais seriam as operações lógicas que permitiriam afirmar a homossexualidade como posição de enunciação universal" (PRECIADO, 2014 , p. 179)? Seguindo os passos de uma filosofia investigativa, Preciado busca as respostas para essas perguntas nos próprios contornos que Deleuze dá a esse tema. Assim, a ideia principal desse capítulo é a de sugerir que a homossexualidade molecular não trata simplesmente do relacionamento de homens com homens e mulheres com mulheres. Trata-se de quando o homem procura também o que há de masculino na mulher, e a mulher, o que há de feminino no homem, configurando o que ele preza por transversalidade.

Em linhas gerais, Manifesto Contrassexual é relevante para os estudos feministas, de gênero, bem como para teoria queer, por abordar em que medida as diferentes tecnologias de gênero operam para produzir posições de sujeito-corpo e as formas através das quais esses sujeitos-corpo resistem à normalização. Ou seja, o que interessa a Preciado é como essas tecnologias falham e, de um modo ou de outro, falham constantemente como mostram, por exemplo, as subjetividades intersexuais. Sua preocupação é pensar como são produzidas descontinuidades, como são gerados interstícios, dobras de subjetivação ou incorporações desviantes. Infelizmente, Manifesto Contrassexual chega com 14 anos de atraso no Brasil. De lá para cá Preciado adotou "Paul" como nome social e tem trabalhado constantemente em sua política contrassexual, adotando categorias como classe e raça em suas atuais discussões. Muitas outras questões abordadas neste livro avançaram, como mostra Texto Yonqui (2008), livro no qual se faz uma crítica 
à carta genética e ao fármaco-poder; e Pornotopia (2010), onde se analisa a arquitetura enquanto um dispositivo de biopoder que, a partir dos espaços arquitetônicos organiza a realidade dos corpos. É a partir da trajetória de preparação dessas três obras que Preciado foi reconhecido pela crítica feminista, ganhando inúmeros prêmios e se estabelecendo, de vez, como uma das principais vozes dos estudos de gênero e sexualidade.

\section{Nota}

1 Para Butler, o gênero se dá em atos intencionais, em gestos performativos que geram significados. É pela reiteração de signos, atos e gestos numa dada cultura que ocorre a construção de corpos ditos masculinos e femininos (Judith BUTLER, 1993)

\section{Referênclas}

BUTLER, Judith. Bodies that matter. On the discoursive limits of "sex". New York: Routledge, 1993.
CARRILLO, Jesús. Entrevista com Beatriz Preciado. Revista Poiésis, Niterói, n. 15, p. 47-71, jul. 2010. Disponível em: <http://www.poiesis. uff.br/sumarios/ sumario15.php>. Acesso em 15/02/2016.

HARAWAY, Donna. "Manifesto ciborgue: ciência, tecnologia e feminismo-socialista no final do século XX". In.: SILVA, Tomaz Tadeu da (Org. e Trad.). Antropologia do ciborgue: as vertigens do pós-humano. Belo Horizonte: Autêntica, 2000, p. 37-129.

PRECIADO, Beatriz. Manifesto Contrassexual. Políticas subversivas de identidade sexual. São Paulo: n-1 edições, 2014.

Texto Yonqui. Spain: Huertas. S. A., 2008.

Carmem Silvia da Fonseca Kummer Liblik Universidade Federal do Paraná, Curitiba, PR, Brasil

656 Estudos Feministas, Florianópolis, 24(2): 0, maio/agosto/2016 